R E S E $\tilde{\mathbf{N}}$ A S

\title{
Pensando en la infancia
}

\section{Thinking about childhood}

\section{Noelia Alcaraz Salarirche*}

Recibido: 8 de julio de 2021 Aceptado: 11 de julio de 2021 Publicado: 27 de julio de 2021

To cite this article: Alcaraz, N. (2021). Reseña de: Cómez Mayorga, C. (2021). Pensando en la infancia. Márgenes, Revista de Educación de la Universidad de Málaga. 2 (2), 206-207

DOI: http://dx.doi.org/10.24310/mgnmar.v2i2.12977

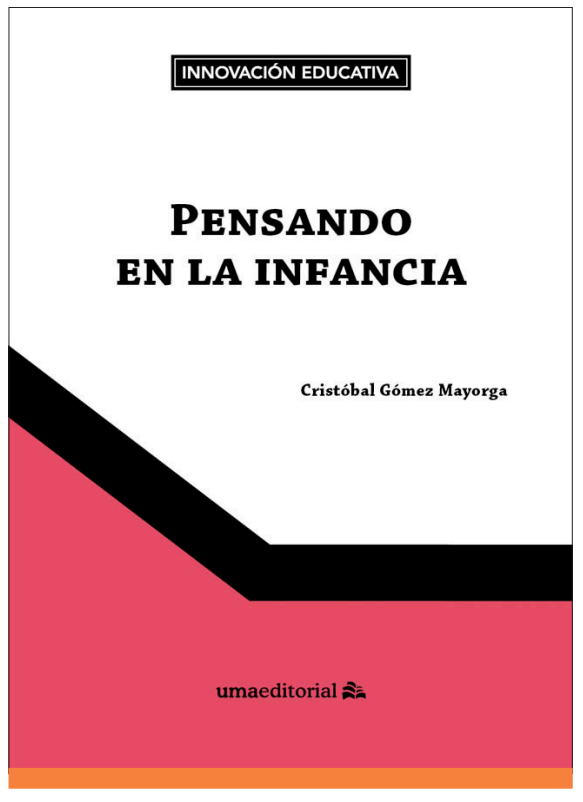

Pensando en la infancia (Gómez Mayorga, C.) 2021, Málaga. Umaeditorial. 170 páginas. ISBN: 978-84-1335-097-4

\section{RESUMEN}

Presentamos la reseña de una obra maestra educativa, pensada y escrita desde el respeto, la sensibilidad, el cuidado, la profesionalidad y la atención a la infancia. Relatada por un maestro, recién jubilado, que quiere compartir con el público la vida en la escuela. Cristóbal Gómez Mayorga, el autor, columnista de esta Revista, nos regala para siempre la voz de su experiencia.

Palabras clave: infancia; educación; escuela; diversidad

\section{ABSTRACT}

We present the review of an educational masterpiece, conceived and written with respect, sensitivity, care, professionalism and attention to chilhoud. It is told by a teacher, recently retired, who wants to share with the public his school 's life. Cristóbal Gómez Mayorga, the author, columnist of this journal, gives us forever the voice of his experience.

Keywords: childhood; education; school; diversity

"Pensando en la infancia" es uno de esos regalos que de vez en cuando la vida pone en tus manos. Leer esta joya de libro donde un maestro como Cristóbal Gómez Mayorga, colaborador habitual de Márgenes, pone por escrito sus reflexiones humanas y profesionales sobre el sentido de hacer escuela, escuela pública y de calidad, como él mismo explica; supone una nueva oportunidad de acercarse desde el respeto y desde una mirada cuidada a la bella tarea de EDUCAR.

Se trata de un libro vivo, que expone de un modo "sencillo", aunque profundo, a veces desgarrador, los complejos 
entresijos de la enseñanza. Y lo hace mostrándonos ciertos límites, acercándonos a las fronteras en las que todo profesional de la educación se mueve.

Una lectura muy útil, tanto para quienes se encuentran actualmente embarcados en el ejercicio educativo, como para el quehacer de los futuros profesionales de la educación.

El autor aborda cuestiones claves del ámbito pedagógico y logra con un lenguaje asequible para todos los públicos, desmenuzar las entrañas de esa tarea de educar; combinando el discurso pedagógico argumentado en las posturas teóricas del paradigma socio-constructivista, con los ejemplos de carne y hueso del día a día en su escuela.

La obra es un "baile” de reflexión teórica-práctica/práctica-teórica, que ofrece a sus lectores y lectoras, la oportunidad de asomarse por la mirilla de un aula de infantil, primero, y de un aula de pedagogía terapéutica, después; permitiéndonos un acercamiento a la realidad educativa, a veces alejada de los planes de estudios universitarios. Ofreciendo la oportunidad de repensar las prácticas educativas, de cuestionarnos el “estatus quo" de la educación; de aceptar la duda y la incertidumbre como compañeros de viaje; de apostar por el existir en la escuela más que por el escribir para la Administración; de priorizar lo que sienten las personas frente a la urgencia de los diagnósticos y las etiquetas. Y lo hace yendo y viniendo del argumento teórico al ejemplo práctico, vivido.

El autor pone a disposición del público, no solo una serie de recursos educativos, más que estudiados y fundamentados en la literatura, como es el caso de las regletas de Cuisenaire o la asamblea, sino las reflexiones en torno a estos recursos. Nos permite ver lo que hay debajo, lo que hay detrás; el corazón y las tripas de prácticas, a veces estereotipadas, que necesitan con urgencia una revisión de su ser y su sentido.

Del mismo modo, podemos encontrar pasajes y alusiones a autores y autoras, así como a obras clásicas, tales como "el Principito", que nos ofrece la posibilidad de releer clásicos con una mirada educativa. El autor, a través de sus vivencias, nos pasea por ello.

Leer el libro de Cristóbal es, casi, como conversar con él. Es como abrir una de sus cajas piscomágicas y descubrir la voz de un maestro jubilado que ha dedicado su vida a mejorar las experiencias escolares y vitales de sus pequeños estudiantes y que, ahora, pensando en la infancia, comparte con el público, de forma generosa, esa parte de su vida, dejando una huella de sus huellas.

En definitiva, Cristóbal, a través de la palabra escrita, de la suya y de la de sus criaturas, recoge un grito de auxilio de la escuela actual, a la vez que muestra los posibles de una nueva escuela. Visibilizando lo difícil, pero necesario, útil, natural y bello, que es, educar en la diversidad, o convertir los conflictos en oportunidades.

Por todo ello, la obra desprende un enorme valor para cualquier persona que esté dispuesta a pensar en/sobre Educación. Gracias maestro. ¡Disfruta de tu jubilación! 